\title{
Social Inheritance of Fear
}

\section{Manol Manolov, Ivan Stoyanov, Zlatinka Georgieva}

Department of Psychology, “St. Cyril and St. Methodius”, University of Veliko Tarnovo, Veliko Tarnovo, Bulgaria

Email: manolov.manolov@gmail.com, ivan790@abv.bg, zl.georgieva@gmail.com

How to cite this paper: Manolov, M., Stoyanov, I., \& Georgieva, Z. (2020). Social Inheritance of Fear. Open Journal of Social Sciences, 8, 1-15.

https://doi.org/10.4236/jss.2020.89001

Received: July 21, 2020

Accepted: August 29, 2020

Published: September 1, 2020

Copyright (c) 2020 by author(s) and Scientific Research Publishing Inc. This work is licensed under the Creative Commons Attribution International License (CC BY 4.0).

http://creativecommons.org/licenses/by/4.0/

\begin{abstract}
Fear exists regardless of the person's level of development or the culture of a people. Although it is an inevitable part of our lives, it does not mean that we are constantly aware of this fact. On the other hand, it seems always present and ready to invade our minds at any moment. Throughout our life, we learn to avoid it by applying various techniques and methods to push it away, to suppress or deny it. When we grow up, we have the mechanisms to deal with our fears, but just when we have successfully dealt with at least one of them, often a new one appears, and we sometimes go into a vicious circle that is difficult to change. Then the question arises of where do children's fears come from? The present study in its first part presents an attempt for theoretical representation related to the experience of fear. In the other part, it presents an empirical study conducted among 126 parents. The research searches the link between the personal characteristics of parents and the temperamental characteristics of children. It's related to the theory of social inheritance which is part of project funded under Contract No КП-06-M25/4 of 12.17.2018 concluded with the Research Fund of the Republic of Bulgaria. The report only looks at the connections that concern social inheritance of fear.
\end{abstract}

\section{Keywords}

Social Inheritance, Fear, Developmental Psychology, Emotional Development

\section{Introduction and Theoretical Formulation}

The reasons for conducting this research are several:

- More and more empirical data in the context of epigenetics show the influence of the environment on the biological changes in the individual (there is a change in DNA depending on environmental factors, which are passed on to future generations).

- Theoretical statements in sociology and economics (where social inheritance is studied) do not provide sufficient clarity about the specific impact on 
intrapersonal processes and experiences of the child in the family. Rather, the emphasis is on external conditions on professional development.

Therefore, the implementation of the project provides an opportunity to consider some prerequisites related to the personality of the parents, which are related to the more intense manifestations of certain traits in the child. The significance of the present study is the presentation of the relationship between personality traits and the way in which they are reflected by the child through the formation of emotional or behavioral reactions to the environment. All this can be a prerequisite for more in-depth experiences, which can lead to lasting consequences.

In light of the psychoanalytic school and its representatives in the person of Wilhelm Reich and Fritz Riemann, we are looking for the underlying fears that have remained unprocessed in the grown-up child, trying to answer a hypothesis that formed after a research on social inheritance. Hypothesis: It is assumed that formation and overcoming child fear are influenced by a certain type of reaction of parents, depending on their character type.

\subsection{Wilhelm Reich's Theory}

Brief description of the character structure of man according to Wilhelm Reich.

W. Reich revises the classical Freudian model of character structure by arranging it concentrically and not vertically. According to him, character is a key concept in the analysis of psychic structure. In the process of the psychoanalytic theory, as a differentiation from Z. Freud's theory, the "resistance" phenomenon emerges, which is seen as manifestation of the death instinct. He introduces the concept of "character resistance" manifested in the individual irrespective of the origin of their neurosis. He also defines this personality structure as a defence mechanism. Therefore, the person's character functions as an "armour", which resists both the impulses coming from the biological centre, and the stimuli coming from the outside world. Reich assumes that the character creates defence against anxiety and concern, which emerge in case of strong sexual desires and instincts and are accompanied also by fear-fear of desire and fear of punishment. This type of protection against the emerging fear is temporary or constant suppression of sexual impulses. W. Reich argues that the character turns into a permanent and automatic defence against the impulses constantly arising from the personality's core. The patient's resistance to the therapy is not a result of a manifested death instinct, but is a natural reaction in the attempt to protect themselves from losing their individuality. Therefore, each person has their protective features, i.e. their characteristic armour. So conflicts, which are inevitable in certain periods of a one's life, always leave traces of rigidity in the character, i.e. making the personality inflexible in the adaptation to the changing conditions of the environment. The "armour" as a character trait is not a system of neurological symptoms, these are guilt, fear, anxiety, etc. and are experienced as phenomena outside the personality, while the neurotic traits of the character, 
such as forced need for dominance, need for love, etc. are experienced as inherent personality elements. The character armour is based on rational and efficient mental processes, which makes its breaking difficult, because its change leads to transformation of the personality structure.

According to W. Reich, the character structure of a person consists of three concentric layers around one single centre: a biological centre or core, intermediate character layer and surface layer. Its centre, or biological core, is characterised by the categories of sincerity, love, diligence, cooperation. The author assumes that these generic properties lack aggression and destruction, so he does not include them in the person's character, but defines them as a secondary, acquired traits associated with frustration in the course of satisfying one's natural aspirations. "Therefore, under certain conditions of life, in the case of a strong protective armour or a strong authoritarian state, one's natural aspiration for love and happiness may be deformed into hatred and destruction" (Stoykov, 2005: p. 28).

Reich combines all physiological, psychological and social traits into a single unity. He studies the personality as having several substructures: body, social relations, will, emotions, intellect and ego.

According to him, the body is an integral unity of all human qualities and functions: biological, psychological and social. In the analysis, he gives priority to the muscular system, which plays the role of a protective armour.

The social relations are functions of the character. The "little person" perceives the world through the prism of their protective armour. Only the normal genital character has overcome its rigid armour and acts freely and openly in the relations with other people.

The will is not a special subject of Reich's study, but he attaches an important meaning to it in terms of constructive and creative work. He emphasizes the fact that will shall not be detached from the actions. Will is everything that one does out of necessity. According to Reich, what needs to be done and is done by a person is the real expression of will.

The intellect is an integral part of the body and the emotions. It is a biological function and therefore it can be as intensive and powerful as every strong emotion. The full development of the intellect and the related thinking is a function of the normal genital character. The genital character and the intellect are interrelated in the same way as the feeling of guilt and religion, hysteria and superstition, sexual awareness and neuroses. Hence the conclusion that the intellect may work in two directions-focused on the inner world and influenced by the outer world. As a result, it may resist the vital instincts or work for their realization. Reich suggests the thesis that the intellect, in the form of linguistic constructs, often has a protective function. Words are used to "conceal" the vital desires. In extreme cases of such defence, words do not express anything personal, they lose their meaning of adequate communication, while the reaction in the body and muscle armour always corresponds to the real emotions and thoughts. 
The ego is the strong biological core of every person. Most people cannot rationalize and experience their ego because of the physical muscle armour and the intellectual (rational) defence. According to Reich, it is difficult for a person to reach their ego-core, because they identify themselves with what is visible, with what is deformed by the character armour. In other words, one resists to finding out what they really are, because they need to change what they believe they are. This actually means losing the current self-image, an idea which was formed in very early childhood.

In his analysis, W. Reich introduces the concept of "emotional plague" and applies it as a tool to analyse and differentiate between three types of characters: genital, neurotic and carriers of the "emotional plague". The emotional plague is closely related to the neurotic typology, which is essentially a function of character and is well protected by it. In their behaviour, every person may have a range of reactions, where the rational ones are typical for the genital characteristics and the impulsive reactions are associated with the neurotic character. Reich assumes that the character is not determined by manifesting one response or another to a certain stimulus, but by manifesting a certain type of reactions. $\mathrm{He}$ gives examples with parent reactions manifested in divorce situations.

The genital character leads the fight by rational means. In this case, parents are concerned about the child's health. This determines also their mutual decision with whom the child will stay. They take into account the preference of the child for remaining with one of the parents. They do not hide their potential problems, illnesses or social failures. The most important and the main motive for parents with genital character is the biological and social well-being of the child.

In the case of the plague character, the interest of divorcing parents in the child is only decorative. The commitments remain only in words, the real motive is to revenge the other person and deprive them of the opportunity to communicate with the child. Such partners are capable of manipulating the child through intrigue, slander or lie, and if there are no such, they are capable of inventing them. The main motive in this fight is the downright vindictiveness of partners, which are in no way interested in the vital needs of the child.

Parents with neurotic character fight for the child by motivating their behaviour as fear of loneliness or of public opinion, they seek solution of the problem outside themselves and find it in the court decision. Parents with this personality structure usually hide from the child their personal deficiencies, they focus on the weaknesses of the other parent or project non-existent ones to make the other parent unattractive to the child. It is actually when talks about the neurotic parent when Reich describes the natural need of manifesting fear as an emotion ensuing from losing security, power and superiority, which is decisive in the child's development.

Reich assumes that human emotion, in its original manifestation, is an important substructure of the character structure.

It is evident from the given examples that behaviour is an expression of the 
natural needs of man, incited by the energy flows. Their protective armour does not allow the parents to accept and overcome the natural and strong emotions, such as anger or love, which are restricted and deformed. Reich believes that one may discard the blocked emotions, only if they fully experience them. According to him, in certain circumstances, the protective armour frustrates the natural emotions, and natural love becomes aggression, while anger turns into hatred.

In this case, we assume that the parents could transmit their fear of losing power and security to their child.

\subsection{Fritz Riemann's Theory}

In Fr. Riemann's theory we find the opportunity to study fear from his point of view, broadening the character structure theory of W. Reich by trying to describe the impact of parent's character on the formation of child's fear. Because since our birth we start developing our personal fear, determined by the individual living conditions, aptitudes and the surrounding world. Each fear has its development history. If the individual accepts and overcomes fear, they get the opportunity to become more mature. And on the contrary, avoiding fear and evading confrontation with fear leads to stagnation; to a certain degree it stalls the further development and the adult remains a child at the point where they couldn't overcome their fear barriers. Fear always emerges in situations that one cannot manage alone.

Fr. Riemann wrote "... irrespective of the diverse manifestations of the fear phenomenon in different people, there is actually nothing that cannot instil fear in us-when we look closer, we find that these are variants of several precisely defined types fear" (Riemann, 2002: p. 3).

In his book "The basic forms of fear" Riemann (2002) suggests the following classification:

1) The fear of surrendering oneself, experienced as loss of the ego and dependency;

2) The fear of self-becoming, experienced as being unprotected and isolated;

3) The fear of change, experienced as transience and insecurity;

4) The fear of necessity, experienced as finality and bondage.

All possible expressions of fear are based on the above and are related to the four basic impulses, which are part of our being and which also complement and contradict each other in pairs: striving for self-preservation and dissociation from the opposite striving for self-denial and belonging. On the other hand is the striving for permanence and security compared to the desire for change and risk.

It shall be pointed out that the type of fear being experienced and its intensity to a great extent depend on the aptitudes of the person, on the "inheritance" that they have and on the conditions in the surrounding world. The ability to manage fear depends on the physical and the mental and spiritual constitution, as well as on the personal biography of the individual. 
Like with most emotions, the roots of fear are in the family, in which the child grows. In the early childhood, man experiences their most burdensome fears, because a child is still not able to develop resistance forces against them. Often, when a fear becomes too strong or if it emerges at an age when the adolescent is not able to cope with it, then such fear will be difficult to overcome. At that moment it is not easy to activate the positive aspect of fear, when there are problems or stagnation in the child's development. Therefore, help from outside will be needed. This type of support may be different, depending on the adults' behaviour.

A child with loving and caring parents will easily overcome its fears, but if left alone in coping with fear, the consequences will be inevitable. In the world of parents that are sometimes loving, and sometimes indifferent or angry, the child feels fear not of the dark or of loud noise, but fear of not knowing what to expect from the valence of adults' emotions and behaviour. The parent that for some reason leaves the family, nurtures the biggest fear in the child, the fear of being abandoned. Opposite to this stays the fear of "suffocation", when the over-caring parent does not allow freedom to experiment and make mistakes, suppressing the active exploration of reality, then fear takes the form of a phobia and becomes painful and inexplicable. In most situations, the available and often contradictory information coming from adults is not deciphered and is replaced with fantasy. In these cases, the message that the child gets is to be careful because the world is dangerous, and therefore it is forced to live with the fears that parents experience. It cannot recognize the root cause of their emergence and cannot realize that these are not its fears.

In all examples of the influence of adults on the child's fear, the child tries to understand the behaviour of adults. It seeks the interrelation between the cause of their fear and what is happening. Thus, when the child grows up and becomes an adult (parent) it will carry inside the symbol of previous fears it was not able not overcome.

Through the theoretical concept of F. Riemann, we will try to explain how fear can be inherited (influenced) based on the parental character type.

According to F. Riemann, the four major forms of neurosis are: schizophrenia, depression, compulsion neurosis and hysteria. F. Riemann explains that these four personality structures in their original form are normal structures with certain accentuations. But if the accentuation becomes markedly one-sided, it will reach borderline values, which should be considered as distorted forms or extreme variants of these personality substructures.

\section{THE SCHIZOID PERSONALITIES}

The problem of the schizoid personality in terms of fear is the fear of commitment. "They overestimate the impulse of "self-rotation", which in a psychological plain means the impulse of self-preservation and dissociation of the ego. We call these people schizoid" (Riemann, 2002: p. 8).

Characteristic of this type of personality is to keep distance from others and to 
avoid full commitment. If others want to shorten the distance in order to make friends, this is considered trespassing the life space, a threat to the need for independence. In such situation, the fear of human closeness develops, which is typical for the schizoid personality.

Schizoid parents give too little warmth to their children; they are not able to adequately differentiate and respond to their emotional needs, thus ironically ridiculing the expression of feelings. This type of parents easily causes their children to become uncertain, guessing and psychologically revealing their motives, thus inciting self-reflection from very early age. Children are disconcerted by parents' reactions, because they have not learned to recognise them, and that keeps them in constant state of alertness and tension. Children see in the very few opportunities for loving identification, because the love of the schizoid persons is too difficult to attain.

\section{THE DEPRESSIVE PERSONALITIES}

The depressive type of personality has a dominant fear of loss. The fear of isolating distance, of separation, of loneliness. They seek opportunities for closeness and commitment in order to protect themselves from their fear, where the dependency on the other person is what gives them security. Due to this dependency they live a life of constant fear of losing support, they bet everything and transfer the responsibility to others. They see themselves as unable to live without the "other". The fear of loss becomes stronger, even at times of short-term separation, and often their reaction is to panic.

Due to their inability to realize their individuality, they tend to idealize people and particularly the closest ones. "Thus they develop too little imagination for evil in mankind-in others and in themselves; as in order to trust so completely and unconditionally they must suppress doubt and criticism, must make sure these do not become conscious; they steer clear of conflicts, avoid arguments "for the sake of peace", because these threaten to alienate them from the partner” (Riemann, 2002: p. 30).

Mothers with depressive structural circle spoil their children, because of their unrealized fear of loss. They overwhelm them with tenderness and wouldn't dare refuse anything even if it is healthy or necessary to do without it. Such behaviour is observed in women who are disappointed with their marriage or have lost their partner, for them the child becomes the meaning of their whole life. They spoil the children from the very beginning, when they are still babies, they take the bay in their hands every time it cries, they respond to every reaction of displeasure with overwhelming tenderness. While children are growing these mothers stand as a buffer between them and the world, aiming to protect them from everything. They do not accept the children's inevitable effects and react with tears and insults that make children feel guilty. Over time, this behaviour increasingly binds the child to the mother and leads to lack of initiative and waiting for someone else to determine their behavioural reactions. For that reason, it is possible that the child develops passive attitude of expectation and comfort, which is sometimes a sign of hidden depressive conditions. Children 
assume that home is the best place and this weakens their impulse to turn to the world. They expect that the world will continue to spoil them, so the interaction with it often brings them failure. Thus, when they experience their own inability and weakness, they return to the well-known security that their mother offers.

\section{THE COMPULSIVE PERSONALITIES}

The third basic form of fear, which is assigned to the obsessive type of personality is fear of transience. The more one tries to protect themselves from this fear, the stronger it seizes them.

This type of parents suppresses the child's first attempts to develop constructive and artistic abilities. They turn it into a puppet, in education "they think punishment is very important, and this is where their sadistic side often comes to the fore: in the severity of punishments, in the compelling of obedience, in punishments that make sure the child feels the power of the parent and which often humiliate it" (Riemann, 2002: p. 74).

For such parents, it is difficult to recognize the child's right of freedom, which they themselves did not have in their childhood, and while reproducing the tradition in which they grew, they fail to notice that the world has changed and that children grow in a different world. This is how the most severe conflicts arise between generations, these parents demonstrate power and superiority, and have difficulty admitting their own mistakes, assuming that this will destroy their dignity.

\section{THE HYSTERIC PERSONALITIES}

According to F. Riemann, hysterical personalities strive towards change and freedom, they say "yes" to everything new. The hysterical personalities trivialize, avoid and reject reality, they embrace a seeming freedom, which may become dangerous over time. They live in an unreal, illusory world, consisting only of fantasy, and a sort of pseudo-reality.

They often do not realize their real fear-in this case, the fear of necessity and finality. They report fear of open spaces (agoraphobia), fear of enclosed spaces (claustrophobia) or animals phobias. These fears represent shifting the actual fear onto something minor and avoidable. Their actual fear of restriction of freedom "... or of a situation of temptation, for which one is not ready yet" (Riemann, 2002: p. 79).

Parents with hysterical personality structure are fascinating and enthusiastic, spontaneous in expressing their feelings, they easily convince and create in children the belief that life is beautiful. This in turn awakens the expectations of wonders that will happen one day. Parents maintain the illusionary thinking and wishes instead of guiding the child into reality. The difficulties in education are related to the lack of consistency, they swing from spoiling to deprivation and back. When parents have to impose a necessary sacrifice, they give vague promises for the future, which do not provide an opportunity to comprehend the meaning of the message. It is difficult for children to orient, they are not sure what to expect and the reason for that is the parents' changing mood.

Hysteric parents tend to educate "representative" children, to push them to a 
role that will glorify them and enhance their own prestige. Children do not have the right to disappoint them, having to realize the parent's own unfulfilled dreams. Failure leads to loss of parental love. Criticism from children is seen as a personal insult. It is not taken into account, because it impairs their vanity and selfishness.

This type of parents does not develop vital skills and abilities in children. Children do not acquire enough experience in managing crisis situations, which is the beginning of future disappointments in themselves and in life.

Tracing the characteristic traits of the four basic types of fear, we come to the conclusion that over time, every person learns how to use the four possible approaches to handle even one life situation.

To support the above, we would examine three specific cases from the study on the inheritance.

The three children and their parents were observed for a period of three years. At the time of the interview the children were 7 years old, one girl and two boys, with no kinship ties. In a preliminary conversation with the parents, we asked a few questions to their mothers.

We asked these questions to them, because we assume that children are sustainably attached to their mothers.

Attachment is "...a striving to communicate with an adult, through which the child acquires important models (patterns) of common behaviour and skill, i.e. of communication. Children get attached to anyone that they can communicate with, not only to the person who provides physical comfort..." (Madzharov, 2017: p. 70).

According to Izard, the basic reason for fear is uncertainty. Uncertainty may be a result of the unstable attachment of the child to the care giver or the object of attachment, which are the source of the basic sense of security on one hand, and on the other hand, is the sense of uncertainty and fear. In the early childhood, when the personality is formed, the mother figure appears to be the most significant in terms of attachment. For this reason, our questions were associated with raising the child: whether they are doing it alone or with the help of the extended family; the difficulties encountered in looking after and educating the child; the most frequent fear of the child; the way parents handle the child's fear, their attitude and so on.

\section{Brief Case Study Related to Fear}

A question of interest for us is "How do parents help the child cope with the fear of the dark?". In order to make it easier for the parents to understand which type of fear we are talking about, we decided that the most common fear in children is the fear of the dark. At the same time, in the preliminary talk and during the three-year observation of the family relationships, we tried to identify the type of parent that each of the mothers is according to the personality characteristics of F. Riemann. Several cases were studied, which form the basis of the main hypo- 
thesis mentioned above.

In the conversation with the mothers, based on their predominant behaviour, we could recognize the depressive, the schizoid and the hysteric type of personality.

The behaviour (reaction) of the predominant hysteric type of mother for handling her child's fear was through the joke. From the very first times the daughter expressed her fear, her mother started minimizing the situations in which the child could feel afraid of the dark. The lighting in the rooms was switched on before sunset or when someone from the family guessed the wishes of the child. Over time, the mother realized that she is not helping her child, because "I cannot be always there for her". And recently she started using another approach in cases of fear. She used jokes and amusing stories to help the child see the fear in another way.

The mother applied the necessary creative distance that the child needed, because she realized that through drawings she would give a form to her own ideas and desires regarding the situation. In one of the child's drawings, related to the fear of the dark, the entire sheet was taken up by a colourful bed with cover and pillows. When the child was asked "Where is the Dark", the spontaneous answer was "Under the bed! They live there-the mother Dark, the father Dark and their children." "And what colour are they?", "The mother and the father are Black, and the children are White!". This clarification about the colour of fear gives us reason to ask ourselves the question of whether this is the most appropriate way to overcome fear, finding that in the child's imagination fear is not so black, since its children are white. Regarding the absence of human figures, the child explained that the subject of her drawing was Dark, and the Dark has no shape, "It is dark!".

The mother with dominating depressive type of personality helped her son overcome fear by repeatedly telling him how and in what circumstance she herself was afraid the dark when she was a child. In this case, the way to handle the fear of the dark was conveying her own personal experience in overcoming fear. Armed with flash lights in search of the dark, the mother willingly faced the danger together with the child, thus creating in him the ability to overcome fear. She supported and approved every attempt to overcome the negative emotions, but only when they were together. While playing this game (in this adventure), she tried to encourage tolerance for fear. Suggesting him that he has to accept the fact that fear is an inevitable part of life, that there is nothing bad in being afraid from time to time, she also made him remember that she will always beside him.

The attitude of the mother with the schizoid type of personality was to transfer the task for overcoming the fear to the father: "This is men's business". According to us, the father was the dominant depressive type of personality. This assumption is based on the fact that the schizoid and the depressive partners are instinctively drawn to each other. The father was ready to give his whole love and to sympathise with the emotions of both the mother and the child. Thus the 
parent breeds confidence in the child in order to recognize and to acknowledge its independent existence. The fear of the child gives parents the possibility to catch up with something that has never been allowed for them to experience, to trust and feel secure, each in their own way. Through the fear of the child parents feel that the person next to them urgently needs their willingness to love, and according to us, the father understands that he has never dared live as an independent individual, without the fear of loss and the sense of guilt. We cannot describe the exact method that the father applied to handle his child's fear, but we can guess that it was through playing and through selfless love. From the answers given to the "Questionnaire on child behaviour", we can assume that the percentage of child's fears was still very high. The reason for that is the insufficient confidence of the child in the object of attachment (the mother). Because in critical moments, the mother cannot offer the necessary support in overcoming the fear, due to her fear of dependence and impulse for independence.

\section{Empirical Study}

So far, theoretical statements have been presented as part of psychoanalysis, which is also a foundation in connection with the understanding of the contexts of fear that cannot be empirically confirmed. The case studies present the dynamics of work on three cases over a three-year period. The questionnaires, which are also used in the research, were tested with the families. This gives grounds to accept the validity of the hypotheses.

There are various studies that confirm epigenetic mechanisms in fear conditioning and fear learning (Kwapis \& Wood, 2014), (Zovkic \& Sweatt, 2013), (Johansen et al., 2011). All these studies show the prerequisites in life that increase fear and the prerequisites for it to manifest itself in future generations. However, the personal prerequisites that are part of the parental characteristics are not considered. The proposed study offers precisely this view of the "learning" of fear, without any other "crisis" and difficult events to determine it.

As stated in the previous report "The Role of Bulgarian Proverbs in the Modern Family", the questionnaires used in the study of social inheritance are WIPPF (Peseschkian \& Deidenbach, 1988), IBQ (Putnam \& Rothbart, 2006) and SDQ (Goodman, 1997). They study the character features of parents, the temperamental features of children, as well as their strengths and weaknesses in relation to the symptoms that they could possibly manifest. The attention is drawn to the fact that the hypotheses rely on the psychoanalytic theory, but since such a study is actually not possible, the methods used are aimed at maximum approximation to the characteristics given in the theoretical part.

The questionnaires were physically handed over to 250 parents with children. Of them, only 126 valid protocols were returned by 78 parents that are part of a couple and 48 single parents. Most of the parents that live in a couple have participated and completed the test set together. Only in four of the families the answers were given only by the mother. The parents are relatively evenly distri- 
buted according to the number of children, and in the cases of parents with two children, in view of the target group ( $3-8$ years), the child that was studied was the second-born.

Since statistically significant differences were not found between the results of parents living in a couple and those of single parents, the results were examined in their entirety.

This report presents the results regarding fear. Since there are statistically significant correlations with most of the variables, here we represent the regression model of the relation between the fear scale and the WIPPF scales. This model explains $73.9 \%$ of the cases in the sample. The interaction between the variables is shown in Tables 1-3.

Data referring to fear:

- More intensive manifestation of trust as a primary aptitude (increased trust, which probably leads also to uncertainty), the idealistic in emotional behaviour, processing through contacts, directing to others in the emotional relationships and dominant mother parent. In other words, the fear in the child intensifies when the emotional relationships with the parent are managed in the context of others and through maintaining concepts, while the conflicts are processed through contacts. Here, the mother is prevalent. Directing to others most probably increases the child's uncertainty, which also provokes fear experiences.

- The lower levels of fear are observed in the prevailing courtesy as a secondary aptitude, sexuality and tenderness as a primary, sociability with respect to the model examples, justice as a secondary aptitude. Thus, reducing the fear is driven by the higher direction towards primary/secondary aptitudes, directed towards the others and the partner. The child is probably placed to the side, which prevents the development of fear experiences-the lack of interaction. After examining the connections between parents' features and the manifestations in children on the IBQ scale, here is the place to study the correlation between the fear scale and the symptoms, which the child may probably manifest (Table 4).

Table 1. Regression analysis.

\begin{tabular}{ccccc}
\hline \multirow{2}{*}{ Model } & \multicolumn{4}{c}{ Model Summary } \\
\cline { 2 - 5 } & $\mathrm{R}$ & R Square & Adjusted R Square & Std. Error of the Estimate \\
\hline 1 & 0.860 & 0.739 & 0.635 & 0.82925 \\
\hline
\end{tabular}

Table 2. ANOVA analysis.

\begin{tabular}{ccccc}
\hline \multirow{2}{*}{ Model } & \multicolumn{3}{c}{ Model Summary } \\
\cline { 2 - 5 } & Sum of Squares & Mean Square & F & Sig. \\
\hline Regression & 171.451 & 4.899 & 7.124 & 0.000 \\
Residual & 60.513 & 0.688 & & \\
Total & 231.964 & & & \\
\hline
\end{tabular}


Table 3. Coeficients of regression analysis (Parents' WIPPF and IBQ).

\begin{tabular}{|c|c|c|c|c|c|}
\hline \multirow{2}{*}{ Model } & \multicolumn{2}{|c|}{ Unstandardized Coefficients } & \multirow{2}{*}{$\begin{array}{c}\text { Standardized } \\
\text { Coefficients }\end{array}$} & \multirow[b]{2}{*}{$\mathrm{t}$} & \multirow[b]{2}{*}{ Sig. } \\
\hline & B & Std. Error & & & \\
\hline (Constant) & -2.738 & 1.907 & & -1.436 & 0.155 \\
\hline Trust & 2.481 & 0.359 & 0.720 & 6.915 & 0.000 \\
\hline Emotional attitude Idealistic & 1.903 & 0.497 & 0.531 & 3.830 & 0.000 \\
\hline Processing through contact & 0.784 & 0.230 & 0.437 & 3.404 & 0.001 \\
\hline Emotional attitude-We & 1.675 & 0.623 & 0.333 & 2.689 & 0.009 \\
\hline Model-Mother & 0.473 & 0.188 & 0.222 & 2.519 & 0.014 \\
\hline Hope & -0.827 & 0.269 & -0.289 & -3.073 & 0.003 \\
\hline Fantasy & -0.544 & 0.237 & -0.304 & -2.297 & 0.024 \\
\hline Justice & -1.071 & 0.376 & -0.385 & -2.851 & 0.005 \\
\hline Model-WE & -1.123 & 0.307 & -0.493 & -3.653 & 0.000 \\
\hline Sexuality & -1.338 & 0.277 & -0.514 & -4.835 & 0.000 \\
\hline Courtesy & -2.131 & 0.492 & -0.793 & -4.331 & 0.000 \\
\hline
\end{tabular}

Table 4. Correlation between emotional symptoms and fear.

\begin{tabular}{|c|c|c|c|c|}
\hline \multirow{2}{*}{ Fear } & \multicolumn{3}{|c|}{ Correlation } & \multirow[b]{2}{*}{ Prosocial Behavior } \\
\hline & Emotional Symptom & Behavioral Change & HADV & \\
\hline Pearson Correlation & $0.539^{* *}$ & $0.248^{\star *}$ & & \\
\hline Sig. (2-tailed) & 0.000 & 0.006 & & \\
\hline
\end{tabular}

${ }^{*}$ Correlation is significant at the 0.01 level (2-tailed).

It is evident from the table that fear is to a great extent connected with the emotional symptoms, as well as with the changes in behaviour.

The third significant result related to fear is the result of the dispersion analysis (Table 5), which evaluate the differences between parents with one or two children.

In the case of parents with two children, the child's fear has higher values, which is only logical from the point of view of the probable focus of parents on the second child and the desire to compensate any gaps allowed with the first child (the assumption is connected with the ethno-psychological characteristics of Bulgarians). A research analysing the parent styles regarding the meaning of life established that more than $50 \%$ of the respondents find the meaning of their life through the child, leaving their personal and professional development in a static state (Stoyanov \& Manolov, 2018). Thus, the growth of the child may be seen as a form of losing the meaning of life, and in such a situation the second child is perceived as a kind of compensation.

This can also be explained with the emotions that parents feel in terms of the opportunity for a "new experience" in the partner relation, the relationship and the parenthood. This is a form of regressive metamorphosis.

\section{Conclusion}

The balance in the presented theoretical part, which from a psychoanalytic perspective explains that the parents' love for the child is closely related to over 
Table 5. Dispersion analysis.

\begin{tabular}{|c|c|c|c|c|c|c|}
\hline \multirow{2}{*}{\multicolumn{3}{|c|}{ Dependent Variable }} & \multicolumn{3}{|c|}{ Dispersion Analysis (LSD) } & \multirow[b]{2}{*}{ Prosocial Behavior } \\
\hline & & & Emotional Symptom & Behavioral Change & HADV & \\
\hline Fear & One & Two & $\begin{array}{c}0.539^{* *} \\
0.000\end{array}$ & $\begin{array}{c}0.248^{* *} \\
0.006\end{array}$ & & \\
\hline
\end{tabular}

${ }^{* *}$ Correlation is significant at the 0.01 level (2-tailed).

coming fears. In this sense, the child's affection is a factor, which is interrelated with the fear experiences. All of this depends mainly on whether the parent's care helps the child to understand the strange phenomenon that instils fear. A major contribution of the study on fear is the presentation of the components related to the child's experience of uncertainty, which limit its ability for exploration and thus the world remains an unknown place. Here the dominating mother stands out. Her function presumes higher level of anxiety. In this sense, the dynamics of the fear experiences is higher where the anxiety model is dominant. The trust as an aptitude (typical for the mother) and the idealistic (as an emotional attitude) have their respective role in detaching the child from reality. This in turn leads to experiencing uncertainty, and probably also mistrust. The last, from the point of view of the limited ability for orientation in the context of reality, suggested by frustration as a component for achieving success. This is probably influenced also by the unconditional love, which is a function of the mother. It restricts the understanding of the properties and the meaning of phenomena that the child encounters. Trust on the other hand restricts the ability of the child to encounter and fight for "their own", since it is given without being earned.

On the other hand, it is evident that the lower levels of fear are in situations where the parent has higher level of sexuality, which gives higher priority to the relationship with the partner. This shifts the focus to the partner relationship and stabilizes the social role of the parent in terms of equality-none of the parents is dominant. In other words, the parents do not forget that most of all they are partners on a joint mission. It is not surprising that justice is indicated as the main principle in this type of parenthood. On the other hand, the result regarding the model examples is also interesting. When the parents themselves lack focus on their own parents, then the levels of fear in children are lower. This is logical in view of the probable adherence to the current norm, and not to the one transferred from the previous generation.

The main conclusion from this study is that the compensatory behaviour of the mother, the focus on the trans-generational transmission and the possible suppression of a father figure, together with "exalting" the child into an idealistic object with excessive trust, leads to higher levels of fear experiences. In this sense, the depressive type of mother in the Bulgarian sample is seen also as the strongest predictor of a child who would experience more intensive fear. On the other hand, fear is the reason for the child's emotional and behavioural symp- 
toms, and the emotional is more intensively manifested.

The practical contributions of the study bring out several emphases related to family functioning. It is clear from epigenetics that psychotherapy can be a tool to prevent or limit the inheritance of the biological preconditions for fear. Social inheritance from the psychological point of view, in turn, provides a direction in which counseling or therapeutic work with families should be aimed at balancing the roles of parents in the first place as partners, and then the parental roles of mother and father, without a dominant presence to one of the two in the life of the child, and on the third hand the adherence of the child in the spirit of modernity, and not independence on generations backwards.

The limitations of this study are mainly seen in the lack of motivation of parents to complete all forms that were provided to them, and the small number of respondents. In this sense, the perspective is to broaden the research in view of the interesting results that were obtained, which are not related to the fear scale only.

\section{Conflicts of Interest}

The authors declare no conflicts of interest regarding the publication of this paper.

\section{References}

Goodman, R. (1997). The Strengths and Difficulties Questionnaire: A Research Note. The Journal of Child Psychology and Psychiatry, 38, 581-586. https://doi.org/10.1111/j.1469-7610.1997.tb01545.x

Johansen, J. P. et al. (2011). Molecular Mechanisms of Fear Learning and Memory. Cell, 147, 509-524. https://doi.org/10.1016/j.cell.2011.10.009

Kwapis, J. L., \& Wood, M. A. (2014). Epigenetic Mechanisms in Fear Conditioning: Implications for Treating Post-Traumatic Stress Disorder. Trends in Neurosciences, 37, 706-720. https://doi.org/10.1016/j.tins.2014.08.005

Madzharov, G. (2017). Child Psychology Together. Sofia: Kushovaliev Press. (In Bulgarian)

Peseschkian, N., \& Deidenbach, H. (1988). Wiesbadener Inventar zur Positiven Psychotherapie und Familientherapie (WIPPF). Berlin, Heidelberg, New York: Springer Verlag. (In German)

Putnam, S. P., \& Rothbart, M. K. (2006). Development of Short and Very Short Forms of the Children's Behavior Questionnaire. Journal of Personality Assessment, 87, 103-113. https://doi.org/10.1207/s15327752jpa8701_09

Riemann, F. (2002). Basic Forms of Fear. Sofia: Lik. (In Bulgarian)

Stoyanov, I., \& Manolov, M. (2018). Psychology of Parenting Styles in Terms of the Meaning of Living. V. Tarnovo: St. Cyril and St. Methodius University Press. (In Bulgarian)

Stoykov, I. (2005). The Personality Model in Wilhelm Reich's Theory. Sofia. (In Bulgarian)

Zovkic, I. B., \& Sweatt, J. D. (2013). Epigenetic Mechanisms in Learned Fear: Implications for PTSD. Neuropsychopharmacology, 38, 77-93. https://doi.org/10.1038/npp.2012.79 